\title{
AVALIAÇÃO ECONÔMICA COMPARATIVA DE SISTEMAS DE PRODUÇÃO DE GADO DE CORTE SOB CONDIÇÕES DE RISCO NO MATO GROSSO DO SUL ${ }^{1}$
}

\author{
André Rozemberg P. Simões ${ }^{2}$ \\ Altair Dias de Moura ${ }^{3}$ \\ Denis Teixeira da Rocha ${ }^{4}$
}

Resumo - O presente trabalho objetivou analisar comparativamente a eficiência econômica e o risco associado a sistemas de produção de gado de corte nas fases de cria, recria e engorda na região do Alto Pantanal (MS). Para isso, estimou-se a eficiência econômica de cada sistema, seguida da simulação desta sob condições de risco, por meio do método de Monte Carlo. A análise econômica determinística dos sistemas de produção apontou o sistema de recria como o de melhor resultado econômico, enquanto o sistema de engorda apresentou o pior resultado, com margem líquida e lucro/ha negativos. Já a análise dos resultados econômicos sob condições de risco revelou o sistema de cria como o de menor risco, com o sistema de engorda sendo o menos estável, com probabilidade de $28,70 \%$ de apresentar lucro negativo. O sistema de recria apresentou os melhores níveis de lucro ( $\mathrm{R} \$ \mathrm{ha}$ ), seguido pelo de engorda e de cria. Levando em consideração os aspectos de risco e rentabilidade, os resultados sugerem que o pecuarista que desenvolve o ciclo completo estaria adotando um portfólio de negócio que traria estabilidade à empresa em termos de risco e possibilitaria ganho mediano entre os três sistemas analisados.

Palavras-chave: avaliação econômica, risco, pecuária de corte, Mato Grosso do Sul.

\footnotetext{
${ }^{1}$ Recebido em 21/09/2006. Aceito em 19/12/2006.

${ }^{2}$ Professor da Universidade Estadual de Mato Grosso do Sul. E-mail: andrerpsimoes@hotmail.com.

${ }^{3}$ Professor Adjunto do Departamento de Economia Rural da UFV. E-mail: admoura@ufv.br.

${ }^{4}$ Mestre em Economia Aplicada pela UFV. E-mail: denistrocha@hotmail.com.
} 


\section{Introdução}

O agronegócio brasileiro, em especial a pecuária de corte nacional, tem passado por modificações importantes desde o final dos anos 90 até os primeiros anos do século 21. Muitas das mudanças são fruto do processo de abertura de mercados que vários países têm implementado. Um resultado visível desse processo é o aumento da competição dentro do contexto do agronegócio mundial.

Como conseqüência, os produtores rurais, as indústrias de processamento e as redes varejistas estão tendo que se reestruturar de maneira a produzir, comercializar e manter uma coordenação vertical mais eficiente. Somente com essa nova estrutura que se desenhou no cenário do agronegócio é que o Brasil pôde competir, tanto interna como externamente, com produtos de outros países (Simões, 2004).

A eficiência produtiva é um dos pilares para que os negócios agropecuários possam atingir níveis satisfatórios de competitividade. No contexto da pecuária, a busca por aumento da produção através de ganhos de produtividade, em detrimento do aumento do rebanho, tem levado a uma reestruturação dos sistemas produtivos de gado de corte. Essa reestruturação é baseada na eficiência produtiva, sendo esta diretamente relacionada com a eficiência econômica dos sistemas de produção.

A necessidade da busca pela eficiência produtiva é reforçada pela tendência clara de queda nos termos de troca dos pecuaristas nos últimos anos, refletida pelo aumento do custo dos insumos e pela queda no preço pago ao pecuarista. No Mato Grosso do Sul, esse cenário da pecuária tem levado a uma redução na capacidade de investimento e de custeio dos produtores e, em conseqüência, a uma forte descapitalização do setor (Zimmer et al., 1998).

Os novos padrões de produção de gado de corte associados a mercados de produtos e insumos cada vez mais competitivos levaram a um incremento nos custos de produção. Dessa forma, a redução da 
lucratividade do setor de pecuária tornou-se um fator de seleção natural daqueles produtores mais eficientes. Para se manter na atividade, o pecuarista tem tido que reestruturar seus métodos de produção por meio da tecnificação. Nesse contexto, a atividade pecuária tem passado por uma mudança cultural quanto à visão empresarial dos pecuaristas em todo o território nacional. Assim, tem-se notado a necessidade de que as decisões dentro dos sistemas de produção sejam calcadas em informações cada vez mais precisas quanto ao uso de fatores produtivos e seus respectivos preços.

A atividade pecuária pode ser segmentada, de acordo com a idade do animal, em fases de produção denominadas: cria, recria e engorda. Essas fases podem ser desenvolvidas dentro de uma mesma unidade produtiva (fazendas que desenvolvem o ciclo completo) ou por propriedades diferentes, em que o produto de uma fazenda é insumo de outra. Alguns fatores - como região (topografia, fertilidade do solo), preço e disponibilidade de terra, experiência do produtor, valor de comercialização e custos de produção - determinam a estrutura organizacional das propriedades. Não existe no Brasil um padrão de organização a ser seguido, e sim diferentes opções adotadas em cada região.

No Mato Grosso do Sul existem algumas áreas com maior especialização, a exemplo do Pantanal, onde predomina a cria ou cria/recria. Em outras regiões do Estado, há fazendas especializadas tanto na fase de cria como na de recria/engorda, ou somente engorda, sendo esta última menos freqüente e predominante nas áreas de planalto.

No contexto do aumento de competição no setor do agronegócio e busca por eficiência técnica e econômica nos negócios da pecuária, o aprimoramento das técnicas gerenciais das propriedades rurais apresentase como uma possibilidade concreta de se alcançar sucesso na atividade. Esses aprimoramentos podem ser obtidos pela associação de técnicas de avaliação econômica tradicionais às ferramentas, como simulação de risco. 
Especificamente na área de avaliação econômica, diversos trabalhos importantes já foram feitos em relação à avaliação técnica e econômica da produção de gado de corte, diferindo entre si de acordo com a região estudada, o ano de elaboração e o método de cálculo do custo.

Maya (2003) conduziu experimento na fase de recria/engorda, comparando sistemas de produção a pasto com e sem irrigação na região de Piracicaba - SP. Segundo o autor, os sistemas irrigados apresentavam baixa taxa de retorno do capital, podendo, com grande freqüência, ocorrer valores negativos para este indicador, enquanto os sistemas sem irrigação apresentavam taxa de retorno de $4,4 \%$ ao ano. Com base em simulações, esse autor concluiu que a taxa média de retorno do capital empatado foi de $6,9 \%$ ao ano.

Costa (2000) apresentou os dados da avaliação econômica para um sistema de gado de corte de ciclo completo (cria-recria-engorda) na região de Campo Grande-MS, com taxa de retorno do capital de 6,24\% ao ano, correspondendo a um valor de $\mathrm{R} \$ 2.267,00$ ao mês para os donos dos fatores de produção. De acordo com o autor, essa taxa pode variar conforme se altera a estratégia de venda dos animais para alcançar preços melhores e, também, quando se desconsidera o valor do custo de oportunidade da terra.

Mello Filho et al. (2005) calcularam os custos e indicadores econômicos de um sistema de cria-recria-engorda no Estado de Rondônia, encontrando resultados positivos somente para o indicador margem bruta. Os indicadores econômicos que consideravam os custos indiretos como depreciação e custo de oportunidade foram negativos, mostrando que a atividade não foi sustentável no médio prazo nem atrativa economicamente.

Simões et al. (2006) fizeram uma análise comparativa da eficiência econômica de sistemas de produção de gado de corte nas fases de cria, recria e engorda na região de Aquidauana-MS. Esses autores observaram que todos os sistemas foram lucrativos, entretanto o perfil de composição 
dos custos e receitas da fase de engorda foi diferenciado do das demais fases. Os autores ressaltam ainda que a atividade de engorda foi a mais competitiva em termos de rentabilidade por hectare e que estratégias de gestão diferenciadas devem ser adotadas quando se analisam comparativamente os três sistemas em questão.

Mais especificamente na inclusão de técnicas de análise de risco nas avaliações econômicas dos negócios da pecuária, Simões e Moura (2006) estudaram o desempenho econômico de um sistema de recria de gado de corte em regime de pastejo rotacionado na região de Aquidauana$\mathrm{MS}$, mostrando que uma análise sob condições de risco leva a um nível de informação e suporte à decisão bem mais elaborado do que a simples análise determinística de indicadores de desempenho econômico.

Considerando a utilização da avaliação econômica, associada a técnicas de análise de risco, o presente trabalho analisou comparativamente a eficiência econômica e o risco associado aos sistemas de produção de gado de corte nas fases de cria, recria e engorda na região do Alto Pantanal dos municípios de Aquidauana e Anastácio - MS. Para isso, estimaram-se os custos de produção e eficiência econômica para cada sistema, seguido pela simulação desses sistemas sob condições de risco.

\section{Metodologia}

O conhecimento dos custos de produção é essencial para o efetivo controle da empresa e para o processo de tomada de decisão. Assim, o levantamento de custos se constitui em um método de avaliação de desempenho econômico e técnico da atividade produtiva em questão.

A classificação básica dos custos de produção proposta pela teoria microeconômica é em custos fixos e custos variáveis. Os custos fixos são aqueles que estão relacionados a fatores de produção que não podem ser modificados em termos de quantidade utilizada em um curto período de tempo ou ciclo produtivo. Dessa forma, estes custos estão presentes 
na atividade mesmo que a produção seja zero. Fazem parte dos custos fixos: depreciações, custo de oportunidade do capital, taxas etc. (Varian, 2000).

Os custos variáveis referem-se àquelas despesas relacionadas à utilização de insumos que podem ter suas quantidades variando em curto espaço de tempo, ou em um mesmo ciclo produtivo. Assim, o custo variável está relacionado com a quantidade produzida. São exemplos de custos variáveis as despesas com ração, medicamentos, mão-de-obra, fertilizantes etc. (Varian, 2000).

Neste trabalho, a classificação dos custos será feita conforme a proposta do Instituto de Economia Agrícola de São Paulo (IEA-SP), citado por Matsunaga (1976). Essa classificação permite melhor caracterização do perfil econômico da atividade, bem como possibilita tomada de decisões mais acertadas do que o método de classificação tradicional. Segundo essa classificação, têm-se os seguintes itens de custo e receitas:

Receita Total (RT): composta por todas as entradas monetárias provenientes da venda de animais nos diferentes sistemas de produção.

Custo Operacional Efetivo (COE): corresponde aos desembolsos diretos para compra de insumos (concentrados, sal, medicamentos, energia, mão-de-obra contratada etc.).

Custo Operacional Total (COT): encontra-se somando ao COE a depreciação (pelo método linear) de máquinas e benfeitorias, das culturas não-anuais (pastagens), e a remuneração da mão-de-obra familiar, se possuir.

Custo Total (CT): seu valor é determinado quando se soma ao COT a remuneração do capital médio empatado (custo de oportunidade do capital). 
Com base nesses itens de custos e receitas, a classificação do IEA apresenta os seguintes indicadores para avaliação econômica de empresas:

Margem Bruta (MB): RT - COE

Margem Líquida (ML): RT - COT

Lucro (L): RT - CT

A atividade pecuária, assim como qualquer outra atividade de negócios, está sujeita a riscos. O risco reflete a incerteza quanto ao alcance dos resultados planejados previamente, ou seja, reflete a possibilidade de divergência entre o resultado real e o esperado, podendo essa divergência ser devida a vários fatores, de ordem econômica, técnica, política, ambiental, entre outras.

Uma das formas mais utilizadas para tentar dimensionar esse risco é o método de simulação. Este método constitui-se na representação dinâmica de um sistema mediante um modelo e permite o cálculo de diferentes combinações que probabilisticamente podem ocorrer, obtendo-se como resultado uma distribuição de freqüências deste, sendo traduzido em números o aspecto risco pela variância e, ou, semivariância e suas relações (Noronha, 1991).

Nesse sentido, a simulação de Monte Carlo, utilizada neste trabalho, tem sido considerada uma ferramenta de grande utilidade para os tomadores de decisão, ao tratarem de situações sujeitas a risco em seus projetos. $\mathrm{O}$ método de Monte Carlo é um método prático que utiliza distribuição de probabilidade na análise do risco, possibilitando leitura simplificada da interpretação do risco associado aos sistemas de produção. Este método tem comportamento randômico, ou seja, é uma estatística gerada por amostragem causal ou acidental. Dessa forma, a simulação gera, randomicamente, inúmeros valores para as variáveis consideradas incertas (variáveis de entrada), simulando combinações entre elas que levam a resultados (variáveis de saída), que são o foco da análise. 
REVISTA DE ECONOMIA E AGRONEGÓCIO, VOL.5, $N^{o} 1$

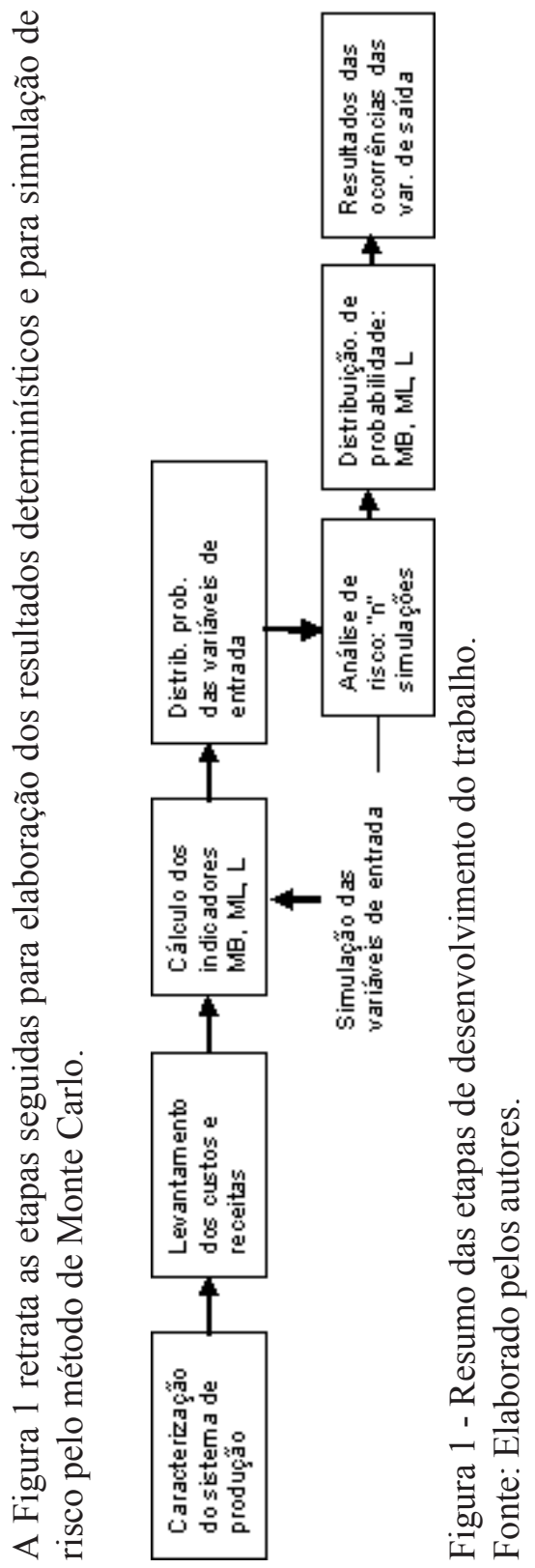


A seqüência de cálculos para realização da simulação de Monte Carlo foi a seguinte (Simões e Moura, 2006):

1. Identificar a distribuição de probabilidade das variáveis independentes (variáveis de entrada) importantes para a análise.

2. Sortear um valor para cada variável, a partir de sua distribuição de probabilidade.

3. Calcular o valor do indicador de escolha (variável de análise) cada vez que for feito o sorteio indicado no item 2 .

4. Repetir o processo até que se obtenha confirmação adequada da distribuição de freqüência do indicador de escolha. Essa distribuição serve de base para a tomada de decisão.

As variáveis de entrada foram escolhidas de acordo com as características de cada sistema de produção pecuária e a participação destas na estrutura de custos e receitas de cada sistema. Por sua vez, a variável de saída (variável de análise) escolhida foi o lucro unitário anual ( $\mathrm{R} \$ / \mathrm{ha})$, por ser um indicador comum entre os três sistemas de produção e poder ainda ser comparado a qualquer atividade agrícola e pecuária.

Neste trabalho utilizou-se a metodologia de estudos de casos, na sua variável de casos múltiplos, sendo levantada uma unidade produtiva para cada fase de criação (cria, recria e engorda). As propriedades estudadas foram escolhidas pelo seu perfil tecnológico e padrão de controle zootécnico/gerencial, de modo que elas se aproximassem ao máximo da realidade encontrada na região, permitindo, portanto, que os resultados encontrados tivessem certo grau de generalização para a referida região. Assim, foram analisadas três fazendas, sendo duas localizadas no município de Anastácio (fases de cria e engorda) e uma em Aquidauana (fase de recria). 
Para se proceder à análise econômica comparativa dos três sistemas de produção (cria, recria e engorda), foram feitos ajustes na escala de produção das fazendas, de modo que todas tivessem um rebanho aproximado de $500 \mathrm{UA}^{5}$. Esses ajustes conservaram o nível tecnológico utilizado em cada sistema e, a partir dai, foram feitas projeções da quantidade de insumos variáveis utilizados, da estrutura física de produção (área, máquinas, benfeitorias etc.) e das receitas obtidas. Foi escolhida a escala de 500 UA, por ser ela a maior encontrada entre os sistemas estudados. Todos os preços considerados no levantamento de dados, o qual foi realizado no ano de 2004, foram corrigidos pelo IGP-DI para junho de 2006.

\subsection{Descrição dos Sistemas de Produção}

\subsection{1 - Sistema de Cria}

$\mathrm{Na}$ fazenda de cria, os animais são criados exclusivamente a pasto, com suplementação mineral durante todo o ano. O sistema tem como objetivo a produção de novilhos(as) (12 meses) para recria, com base em um rebanho nelore.

Localizada no município de Anastácio, a fazenda possui área de 307 ha, sendo 87 ha de Brachiaria decumbens e 218 ha de Brachiaria brizantha. Os outros 2 ha são ocupados por instalações e benfeitorias. O rebanho bovino é composto por 568 cabeças (332 vacas, 61 bezerros (as) até 7 meses, 162 novilhos (as) até 18 meses e 13 touros), sendo ele estabilizado. Dessa forma, encontrou-se a taxa de lotação da ordem de $1,63 \mathrm{UA} / \mathrm{ha}$.

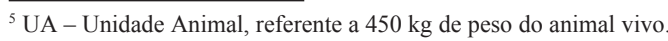




\subsection{2 - Sistema de recria}

Localizado no município de Aquidauana, o sistema de recria utiliza uma área de pastagem de 208 ha, divididos em 12 piquetes de 17,3 ha cada, formados com Brachiaria decumbens, onde se utiliza o sistema de pastejo rotacionado. Os piquetes são cercados com cerca elétrica e a alimentação é basicamente a pasto e suplementação mineral. O sistema utilizou 833 machos nelores, que entraram com peso médio de $180 \mathrm{~kg}$ e saíram com $285 \mathrm{~kg}$. Este sistema de produção apresentou taxa de lotação de $2,4 \mathrm{UA} / \mathrm{ha}^{6}$.

\subsection{3 - Sistema de engorda}

No sistema de engorda os animais são criados em regime de semiconfinamento, tendo o objetivo de produzir boi gordo com aproximadamente 18 arrobas.

Localizada no município de Anastácio, a $18 \mathrm{~km}$ da sede do município, a propriedade possui uma área de 148 ha, sendo 88,9 destes formados com Brachiaria brizantha e 22,2 ha destinados ao plantio de sorgo para produção de silagem. A propriedade conta ainda com um curral de manejo e outro para semiconfinamento, além de um galpão para estocagem de alimentos concentrados. Composta por um rebanho de 442 cabeças da raça nelore, a propriedade apresentou taxa de lotação de 4,2 UA/ha.

\footnotetext{
Pode-se dizer que este sistema faz uso intensivo de tecnologias, sendo a taxa de lotação relativamente alta quando considerada a média da região.
} 


\section{Estudo comparativo dos três sistemas estudados}

\subsection{Resultados Determinísticos (sem inclusão de risco)}

O primeiro passo para o desenvolvimento do presente trabalho foi o levantamento dos custos de produção, seguido da avaliação econômica dos sistemas estudados, não incluindo as variáveis de risco. Os principais índices de rentabilidade econômica — obtidos da análise determinística — dos três sistemas em questão encontram-se na Figura 2.

Em uma primeira análise, somente o sistema de engorda apresentou resultados negativos para algum dos indicadores econômicos estudados. Neste sistema, apenas a margem bruta foi positiva $(M B=R \$ 161,32 /$ ha), o que indica que a atividade é sustentável no curto prazo, pois ela cobre os custos operacionais efetivos. Entretanto, no longo prazo, a situação é adversa ao sistema. Quando se considera o item depreciação na análise, a atividade não se mostra capaz de cobri-la completamente, o que resulta em uma margem líquida negativa $(\mathrm{ML}=-\mathrm{R} \$ 1,99 / \mathrm{ha})$. Assim, não há formação de capital suficiente para repor os bens de produção no final de suas respectivas vidas úteis. Conseqüentemente, o sistema de engorda estudado apresentou "lucro negativo" ( $\mathrm{L}=-\mathrm{R} \$ 128,95 / \mathrm{ha})$, indicando que ele é menos atrativo que a atividade alternativa considerada, que remunera o capital em 6\% ao ano. Dessa forma, observou-se que a atividade não se mostrou sustentável no longo prazo e não foi economicamente atrativa.

Os demais sistemas apresentaram, deterministicamente, resultados positivos para todos os indicadores, refletindo uma superioridade desses sistemas estudados, em relação ao sistema de engorda. 


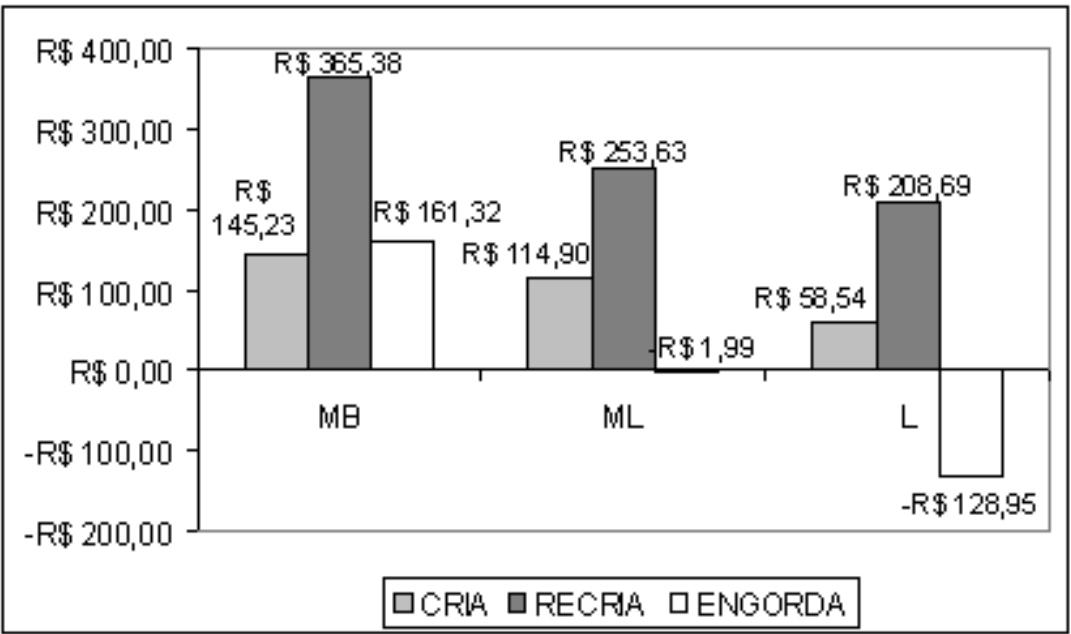

Figura 2 - Índices de desempenho econômico, em R\$/ha, para os três sistemas de pecuária de corte da região do Alto Pantanal sul-mato-grossense - valores de junho de 2006.

$\mathrm{MB}($ margem bruta $)=$ receita total - custo operacional efetivo

$\mathrm{ML}($ margem líquida $)=$ receita total - custo operacional total

$\mathrm{L}($ lucro $)=$ receita total - custo total

Fonte: Dados da pesquisa.

O sistema de cria mostrou-se sustentável no curto e no longo prazo (MB $=\mathrm{R} \$ 145,23 /$ ha e $\mathrm{ML}=\mathrm{R} \$ 114,90 /$ ha), além de ser mais atrativo que a atividade alternativa, ao remunerar o capital empregado numa taxa superior a $6 \%$ a.a. $(\mathrm{L}=\mathrm{R} \$ 58,54 / \mathrm{ha})$.

Por fim, dentre os três sistemas de gado de corte estudados, o de recria apresentou o melhor resultado determinístico. Os indicadores econômicos deste sistema superaram os indicadores dos outros dois, sendo seus valores mais que o dobro dos valores apresentados pelos demais sistemas em estudo. 
Conforme já comentado, esses resultados refletem um instante de tempo de cada sistema de produção, sendo possível que eles se alterem e até mesmo se invertam quando se consideram as probabilidades de ocorrência das variáveis que impactam significativamente os custos e receitas de cada sistema. Por isso, a seção a seguir tem o intuito de mostrar exatamente esse impacto no indicador de rentabilidade.

\subsection{Resultados Probabilísticos - Sob condições de risco}

Após a elaboração da avaliação determinística, deu-se início ao processo de elaboração dos dados para análise de risco, utilizando o método de simulação de Monte Carlo. A escolha das variáveis de risco para cada sistema de produção foi baseada na importância delas para os sistemas, tanto em termos técnicos como econômicos. Dessa forma, as características técnicas de cada sistema e as participações percentuais dessas variáveis nos custos de produção, bem como seu impacto sobre a receita de cada atividade, foram os critérios de escolha utilizados. Os percentuais de composição dos custos e das receitas de cada atividade foram obtidos de Simões et al. (2006). No caso do sistema de cria, escolheram-se três variáveis de risco: custo da mão-de-obra (salário) (9,24\% do custo de produção) e preços de venda dos bezerros (animal de 8-12 meses com $180 \mathrm{~kg})^{7}$ e das bezerras (animal de 8-12 meses com $155 \mathrm{~kg}$, em média) ${ }^{8}$. No caso do sistema de recria, foram escolhidas as variáveis preço pago pela mão-de-obra (salário) $(3,59 \%$ do custo de produção), preço de compra do bezerro ( $77,48 \%$ do custo de produção) e preço de venda do garrote (animal de 18 a 24 meses com $285 \mathrm{~kg}$, em média) $)^{9}$. Por fim, escolheram-se as variáveis preço pago pela mão-deobra (salário) $(3,70 \%$ do custo de produção), preço de compra do boi magro (animal de 24 a 30 meses com $320 \mathrm{~kg}$, em média) (61,60\% do custo de produção) e preço de venda do boi gordo (animal com $540 \mathrm{~kg})^{10}$ para o sistema de engorda.

\footnotetext{
Uma variação de $+10 \%$ nesse indicador causa acréscimo de $19,7 \%$ no lucro obtido.

8 Uma variação de $+10 \%$ nesse indicador causa acréscimo de $11,2 \%$ no lucro obtido.

9 Uma variação de $+10 \%$ nesse indicador causa acréscimo de $91,7 \%$ no lucro obtido.

${ }^{10}$ Uma variação de $+10 \%$ nesse indicador causa acréscimo de $126,16 \%$ no lucro obtido.
} 
Com o intuito de comparar os três sistemas de produção, escolheu-se o indicador lucro/ha ( $\mathrm{R} \$ / \mathrm{ha})$ como a variável de saída para análise dos resultados. As simulações para os sistemas de produção pecuária estudados basearam-se em dados mensais de nove anos (1997 a 2005) ${ }^{11}$

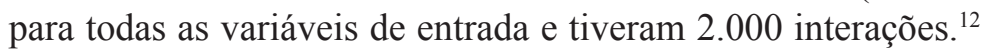

Tabela 1 - Lucro $(\mathrm{R} \$ /$ ha) para três sistemas de produção de pecuária de corte na região do Alto Pantanal sul-mato-grossense, sob condições de risco

\begin{tabular}{ccccc}
\hline Sistema & Mínimo & Média & Máximo & Coef. de Variação \\
\hline Cria & $\mathrm{R} \$ 60,99$ & $\mathrm{R} \$ 143,26$ & $\mathrm{R} \$ 216,27$ & $19,47 \%$ \\
\hline Recria & $-\mathrm{R} \$ 735,95$ & $\mathrm{R} \$ 269,06$ & $\mathrm{R} \$ 1.375,91$ & $135,38 \%$ \\
\hline Engorda & $-\mathrm{R} \$ 1.095,38$ & $\mathrm{R} \$ 211,03$ & $\mathrm{R} \$ 1.331,66$ & $206,41 \%$ \\
\hline
\end{tabular}

Fonte: Dados da pesquisa.

Em termos de dispersão dos dados e valores máximos, médios e mínimos para a variável lucro (Tabela 1), as simulações indicaram o sistema de cria como o de menor risco, apresentando menor amplitude dos valores simulados em relação à média, retratada no menor coeficiente de variação $(19,47 \%)$ entre os sistemas estudados.

Adicionalmente, o sistema de cria foi o único que não mostrou resultados de lucro negativo, o que, considerando os dados simulados, indica que o produtor que se dedica a esse sistema não se arrisca a obter resultados negativos de lucro. Esse resultado não significa dizer que esta atividade está livre de risco de lucro negativo; entretanto, ressalta-se que, considerando esses valores de preços e as variáveis de entrada eleitas para a simulação, não se verificou essa situação. Pode-se afirmar que esta fase da pecuária (cria) apresentou risco significativamente menor que o das outras duas.

11 Fonte: Anualpec (FNP Consultoria).

12 Esse número de interações levou a um nível de amostragem considerado suficiente (i.e., menos de 1,5\% de diferença entre os valores simulados da variável de saída). 
Por sua vez, o sistema menos estável em termos dos resultados de lucro/ ha foi o de engorda. $\mathrm{O}$ alto risco desse sistema pode ser observado no seu coeficiente de variação: da ordem de 206,41\%. Esse elevado risco é reflexo da combinação de amplitude de variação dos preços de mercado das variáveis, preço de compra do boi magro e preço de venda do boi gordo - principais determinantes do resultado econômico da atividade. Desse modo, a engorda deve ser vista como uma atividade produtiva e tecnológica, porém especial atenção deve ser dada ao aspecto comercial de compra e venda dos insumos e produtos, respectivamente.

Por fim, o sistema de recria, que apresentou maior rentabilidade na análise determinística, obteve condição intermediária sob condições de risco, expressa por seu coeficiente de variação em relação às outras duas fases de criação, mas com valor elevado (135,38\%), sendo sua média positiva para o indicador analisado (lucro/ha).

Em termos do valor mínimo de lucro, o sistema de recria apresentou valor negativo (lucro mínimo/ha $=-\mathrm{R} \$ 735,95$ ), porém superior ao sistema de engorda, indicando que este último, além de ser o de maior risco, apresenta também possibilidade de maior prejuízo (lucro mínimo/ha = $\mathrm{R} \$ 1095,38)$ entre todos os sistemas simulados.

Uma das informações mais relevantes que a simulação de Monte Carlo fornece são as curvas acumuladas de probabilidade para as variáveis de análise. No presente estudo, tais curvas mostram qual é a probabilidade de se obter lucro inferior e, ou, superior a um determinado valor. Comparando os sistemas de produção pecuária em termos das suas curvas de probabilidade acumulada (Figura 3), referentes ao ponto de lucro normal (igual a zero), percebe-se, novamente, que o sistema de maior risco para o pecuarista é o de engorda, seguido pelo de recria e, posteriormente, pelo de cria (menor risco). 


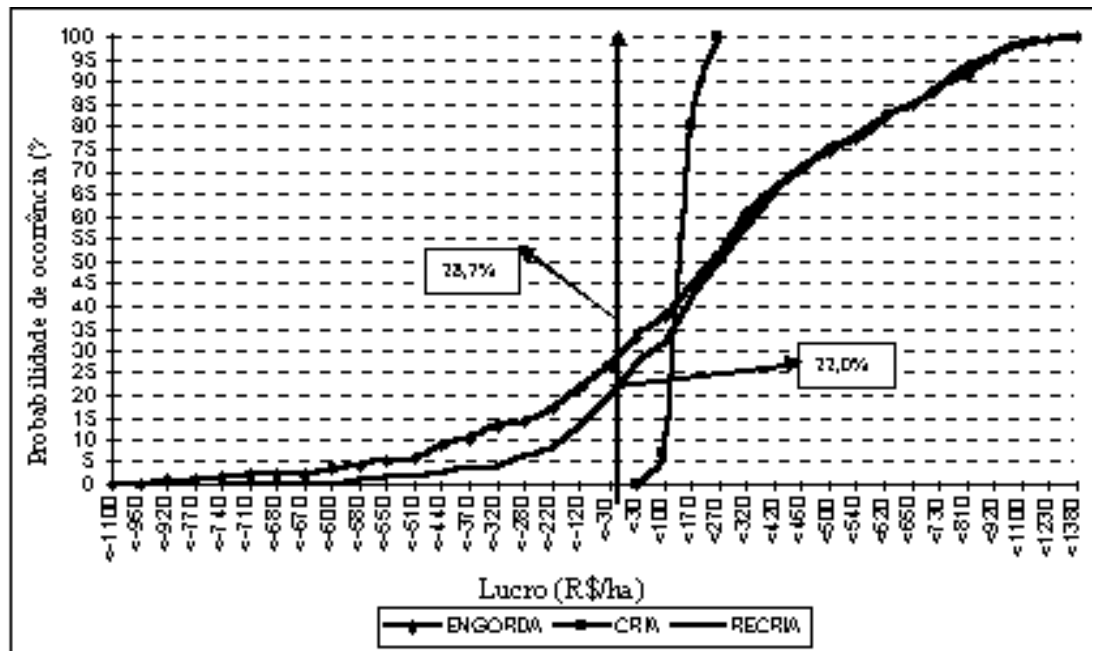

Figura 3 - Curvas de probabilidade acumulada dos valores de lucro $(\mathrm{R} \$ / \mathrm{ha})$ referentes aos sistemas de cria, recria e engorda (pecuária de corte) no Mato Grosso do Sul.

Fonte: Dados da pesquisa.

A análise dos três sistemas de produção pecuária estudados (cria, recria e engorda) para a região do pantanal sul-mato-grossense revelou o sistema de engorda como o de maior risco entre eles, apresentando maior chance de obter lucro abaixo de zero ( $28 \%$ de probabilidade). Apesar de apresentar possibilidade de obter lucro elevado (lucro máximo/ha $=\mathrm{R} \$$ $1.331,66$ ), semelhante ao sistema de recria (lucro máximo/ha $=\mathrm{R} \$$ $1.375,91)$, o sistema de engorda apresentou o menor valor mínimo possível (lucro mínimo/ha =-R $\$ 1095,38$ ), o qual foi bem inferior aos obtidos nos outros dois sistemas $($ cria $=\mathrm{R} \$ 60,99$; recria $=-\mathrm{R} \$ 735,95)$. O sistema de recria, por sua vez, mostrou possibilidade de obtenção de lucro elevado (maior entre os sistemas estudados), ao mesmo tempo em que apresentou risco mediano, comparado com os outros dois.

Por fim, o sistema de cria foi o único a não apresentar possibilidade de obtenção de lucro negativo, somado ao fato de ter apresentado o menor coeficiente de variação dos resultados simulados dentre os sistemas 
estudados (menor risco). Entretanto, esse sistema apresentou lucro máximo reduzido ( $\mathrm{R} \$ 216,27)$, se comparado com os outros dois.

Os resultados mostram, portanto, que a relação risco-retorno está bastante clara nos sistemas estudados. O sistema de engorda pode conferir lucros altos por hectare, mas tem alto risco de fracassar, enquanto, no outro extremo, o sistema de cria apresentou-se como um negócio de baixo risco, mas também de baixo retorno.

Analisando a estrutura de custo montada para o desenvolvimento do estudo, podem-se associar esses comportamentos de risco à parcela de custos oriundos do capital estável e aquela oriunda do capital circulante. Percebe-se que, na estrutura de custo do sistema de cria, 55,13\% dos custos são associados ao capital estável, enquanto os restantes $44,87 \%$ são custos associados ao capital circulante. Dessa forma, o sistema de cria apresenta-se mais protegido das oscilações de preço do mercado que influenciam os custos de produção, visto que boa parte de seus custos de produção decorre da utilização de capital estável (instalações, rebanho reprodutor, máquinas etc.), cujos valores (ou preços associados a ele) não oscilam no mercado. A explicação para isso está no fato de que esses itens de custo, associados ao capital estável, são comprados entre períodos de tempo mais longos (vida útil relativamente mais longa quando comparado ao capital circulante).

No outro extremo, o sistema de engorda apresenta estrutura de custos em que os gastos associados ao capital circulante (custos variáveis) respondem por $90,47 \%$ do custo total (CT), o que faz esse sistema ser altamente dependente das oscilações de preços do mercado, principalmente do mercado do boi magro, uma vez que a reposição deste no plantel representa mais de $60 \%$ do CT. Assim, os custos desse sistema estão intimamente ligados às oscilações mais freqüentes de preços dos insumos ao longo dos anos.

O sistema de recria, por sua vez, mostra-se semelhante ao sistema de engorda, apresentando mais de $90 \%$ do custo de produção associado ao 
capital circulante. Novamente, o item de maior peso é a compra dos animais de reposição (bezerros para recria), responsável por $77,48 \%$ do CT, o que torna a atividade altamente dependente das variações de mercado, principalmente com relação ao preço dos bezerros para reposição.

Tomando como base os dados simulados, percebe-se que as fazendas de ciclo completo (propriedades que incluem os três sistemas: cria, recria e engorda) apresentam um balanço entre risco e retorno na atividade. Portanto, ao adotar os três tipos de sistema dentro do seu negócio, o pecuarista estaria adotando um portfólio de negócio que traria estabilidade para a empresa em termos de risco e possibilitaria ganho mediano nos três sistemas analisados.

\section{Conclusão}

O resultado determinístico da avaliação econômica dos sistemas de produção de gado de corte de três estudos de casos (três fazendas, sendo uma de cria, outra de recria e a última de engorda) na região do Alto Pantanal sul-mato-grossense, para o ano de 2006, mostrou que a atividade de engorda foi a que apresentou menor rentabilidade quando comparada às atividades de cria e recria, mostrando-se ainda viável somente no curto prazo, uma vez que não foi capaz de capitalizar-se para repor o capital de produção permanente, e apresentando remuneração do capital menor que $6 \%$ ao ano.

$\mathrm{Na}$ seqüência, as atividades de cria e recria mostraram-se economicamente atrativas, visto que remuneraram o capital empatado para a produção a uma taxa maior do que a considerada como alternativa ( $6 \%$ a.a.). Ressalta-se ainda que, dentre estas duas, a atividade de recria foi a mais atrativa.

Em razão das suas características, a análise determinística de um investimento apresenta uma avaliação parcial da realidade produtiva e 
pode levar o tomador de decisão a avaliações imprecisas. Um refinamento nas avaliações de investimentos pode ser alcançado através da análise probabilística, em que se leva em conta o comportamento de variáveis relevantes utilizando-se séries históricas. Seguindo a análise probabilística, por meio do método de Monte Carlo, o coeficiente de variação do indicador lucro/ha apontou que a atividade de cria estudada foi a mais estável, seguida da recria e engorda. Os resultados encontrados ficaram de acordo com a relação de risco/retorno, quando se comparam as atividades de recria e engorda com a atividade de cria. Apesar de mostrarem maior volatilidade no indicador lucro/ha, as atividades de recria e engorda apresentam possibilidades de ganhos muito maiores do que o sistema de cria.

A atividade de engorda foi a que teve maior probabilidade de ocorrência de resultados de lucro/ha menor que zero $(28,7 \%)$, seguida da de recria $(22,05 \%)$ e cria ( $0 \%)$. Esse resultado de ocorrências de lucros negativos já era esperado, uma vez que reflete a relação direta entre risco e retorno, bem como a significativa diferença de estrutura de custos e receitas obtidas em cada sistema de produção.

\section{Referências}

COSTA F.P. Avaliação econômica. In: MADUREIRA L. D. Dia de Campo - Sistema de Produção de Carne com Nelore. Campo Grande, 2000. EMBRAPA-CNPGC. Disponível em: <http:// www.cnpgc.embrapa.br>. Acesso em: mar 2006.

FNP CONSUltoria. Anuário da Pecuária Brasileira ANUALPEC. São Paulo, Anos Consultados: 1998 a 2005.

MATSUNAGA, M. et al. Metodologia de custo de produção utilizada pelo IEA. São Paulo: Agricultura em São Paulo, 1976. 
MAYA F. L. A. Produtividade e viabilidade econômica da recria e engorda de bovinos em pastagens adubadas intensivamente com e sem o uso da irrigação. Piracicaba. - 2003. 94 f. Dissertação (Mestrado em Agronomia) — Escola Superior de Agricultura "Luiz de Queiroz", 2003.

MELlO FILHO G. A.; COSTA F. P.; CORREAA E. S.; PEREIRA M. A.; CEZAR I. M.; SILVA NETTO F. G. Custo de produção de gado de corte no estado de Rondônia. Campo Grande: EMBRAPA, 2005. (EMBRAPA-CNPGC). Disponível em: <http:// Www.cnpgc.embrapa.br>. Acesso em: mar 2006.

NORONHA, J. F. Projetos agropecuários: administração financeira, orçamentação e avaliação econômica. São Paulo: FEALQ, 1991.

SIMÕES, A. R. P.; GAMA, F. F. C.; CANUTO, N. G. D.; CARVALHO, D. M. G. Avaliação econômica comparativa de sistemas de produção de gado de corte na região de Aquidauana - MS. In: CONGRESSO DA SOCIEDADE BRASILEIRA DE ECONOMIA E SOCIOLOGIA RURAL - SOBER, 44., 2006. Anais... Fortaleza, CE: 2006.

SIMÕES A. R. P.; MOURA A. D. Análise de risco do desempenho econômico de um sistema de recria de gado de corte em regime de pastejo rotacionado. Revista de Economia e Agronegócios (REA), v. 4, n. 1, p. 75-97, janeiro/março 2006.

SIMÕES A. R. P. Rastreabilidade da carne bovina como condicionante da rentabilidade da cadeia produtiva: um estudo de caso no Estado de Goiás. In: CONGRESSO DA SOCIEDADE BRASILEIRA DE ECONOMIA E SOCIOLOGIA RURAL - SOBER, 42., 2004. Anais... Cuiabá, MT: 2004.

VARIAN, H.R. Microeconomia: princípios básicos. Rio de Janeiro: Campus, 2000. 


\title{
ZIMMER, A. H.; EUCLIDES, V. P. B.; EUCLIDES FILHO, K.; MACEDO, M. C. M. Considerações sobre índices de produtividade da pecuária de corte em Mato Grosso do Sul. Campo Grande: EMBRAPA-CNPGC, 1998. 53p.
}

\begin{abstract}
The present work aimed to analyze the economical efficiency and the risk associated with three different cattle production systems (Cow-calf, Rearing and Finishing) in the Alto Pantanal (MS) Area. For that, the economical efficiency of each system was assessed and then the Monte Carlo risk simulation method was performed. The deterministic analysis showed that the Rearing system was the most profitable while the Finishing system presented the worst profit result. The Cow-calf system obtained an intermediate profit result. The risk economical analysis revealed the Cowcalf system as the lower risky system. On the other hand, the Finishing system showed the higher risk, presenting $28,7 \%$ of probability to obtain negative profit. The Rearing system showed the better level of profits $(\mathrm{R} \$ / \mathrm{ha})$ follow by Finishing and Cow-calf system. Considering the risk and profitable aspects, the results suggest that farmers who develop the three systems together (full cycle) would be adopting a kind of business that would provide more risk stability and intermediary gains.
\end{abstract}

Keywords: cattle production systems, economic efficiency, Monte Carlo risk simulation. 